\title{
Coronavirus (COVID-19) infection - impact on cardiovascular system
}

1) School of Pharmacy, Faculty of Science and Engineering, University of Wolverhampton, United Kingdom
DOI: $10.15386 / \mathrm{mpr}-1900$

Manuscript received: 14.09.2020

Received in revised form: 22.02.2021

Accepted: 25.03.2021

Address for correspondence:

Hana.Morrissey@wlv.ac.uk

This work is licensed under a Creative Commons Attribution-NonCommercialNoDerivatives 4.0 International License
Mariam Ahmed, Patrick Anthony Ball, Hana Morrissey

\begin{abstract}
Aim. This review aimed to explain novel coronavirus (COVID-19) infection impact on cardiovascular system and patients management in community and primary care settings.

Method. Literature search and review limited to 2020 of published papers identified dealing with Coronavirus and cardiovascular disease.

Results. Coronavirus is a large family of positive-sense, enveloped, single-stranded RNA viruses that belong to the Nidovirales order. Covid-19 refers to infection with the SARS-CoV-2 variant. Myocardial injury has a considerable association with mortality outcomes for COVID-19 infection. The prognosis of patients with underlying cardiovascular diseases, who had not sustained myocardial injury was relatively favourable. Inflammation may also be a potential mechanism for myocardial injury. So far, current evidence suggests statistically significant associations between cardiac injury and mortality in patients with COVID-19. Whether this is mediated by destruction of angiotensin converting enzyme 2 in heart cells or by other mechanisms, is being investigated.
\end{abstract}

Conclusion. In patients with underlying cardiovascular diseases, aggressive treatment for COVID-19 should be considered and clinicians should be aware of the significantly increased risk of serious infection and worse prognosis in this patient group. New evidence and studies are continually emerging and will confirm or refute our current understanding about COVID-19 impact. Primary care practitioners are urged to continue to monitor the evolving evidence to appropriately manage their patients who are at risk of, or currently diagnosed with cardiovascular conditions.

Keywords: Coronavirus (SARS-CoV-2), COVID-19, Myocardial injury, Inflammatory response, angiotensin converting enzyme 2 (ACE2)

\section{Introduction}

Coronavirus particles contain four main structural proteins: the spike $(\mathrm{S})$, membrane $(\mathrm{M})$, envelope $(\mathrm{E})$, and nucleocapsid $(\mathrm{N})$ proteins [1]. The life cycle of the virus within the host consists of 5 steps: attachment, penetration, biosynthesis, maturation and release. The initial attachment of the coronavirus to the host cell is introduced by interactions between the $\mathrm{S}$ protein and its receptor. Receptor binding differs between types of coronavirus. Once receptor binding has occurred; the virus gains access to the host cell's intracellular fluid via endocytosis or membrane fusion (penetration). This is generally accomplished by an aciddependent proteolytic cleavage of the $\mathrm{S}$ protein by a protease, followed by fusion of the viral and cellular membranes [2].

The Coronavirus Study Group of the International Committee on Taxonomy of Viruses (2020) proposed the newly emerged coronavirus be named as 'Severe Acute Respiratory Syndrome Coronavirus 2 (SARS-CoV-2) and shortnamed as COVID-19 to identify the year of the pandemic. Following the binding 
of SARS-CoV-2 to the host protein, the spike protein undergoes protease cleavage, the membrane is stabilised, and the virus is made ready to enter the host cell [3].

This review aimed to explain novel coronavirus (COVID-19) infection to allied healthcare professionals, including pharmacists, who are practicing in community and primary care setting.

\section{Method}

This was a critical review of the current literature on COVID-19 published before October 2020. A literature search was performed using Pubmed $\AA$, Google $\AA$ Scholar,

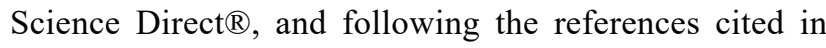
papers identified. The search was limited to 2020 and to papers relating to COVID-19 and Cardiovascular disease. Most of the studies found were available online ahead of publication. Data basis were searched using keywords such as COVID-19, myocardial injury, and angiotensin converting enzyme 2 (ACE2).

\section{Transmission}

The transmission ability and estimation of infection of viruses is estimated and tracked using; the basic reproduction number ( $\mathrm{R} 0)$, the effective reproduction number $(\mathrm{R})$ and the control reproductive number $(\mathrm{Rc})$. If $\underline{R O}>1$, then the number of infected individuals proliferates, and an epidemic may arise. The World Health Organization has estimated the R0 for SARS-CoV-2 to range between 2 and 2.5, which is higher than that for Severe Acute Respiratory Syndrome (SARS, 1.7 - 1.9) and Middle East Respiratory Syndrome (MERS, <1); thus indicating that SARS-CoV-2 has a higher pandemic potential. However, some studies have stated the R0 for SARS to be as high as 3.6 [4]. Data shows that the median incubation period of COVID-19 is estimated to be 5.1 days (95\% CI, 4.5 to 5.8 days), and $97.5 \%$ of those who develop symptoms will do so within 11.5 days (CI, 8.2 to 15.6 days) of infection [5].

\section{Pathophysiology}

After gaining entry to the host cell, the viral Ribonucleic acid (RNA) enters the nucleus for replication. Viral mRNA is used to make viral proteins (biosynthesis) by way of specific stages of replicase protein expression, replication, and transcription. The new mature viral particles are then assembled, and released via exocytosis from the host cell, allowing the virus to spread in the infected organism without detection or neutralisation by virus-specific antibodies [1]. Structural and functional analysis showed that the spike for SARS-CoV-2 binds to angiotensin converting enzyme 2 (ACE2), a monocarboxypeptidase membrane-bound enzyme which is present in the lungs, heart, ileum, kidney and bladder. In the lungs, ACE2 is highly expressed on pulmonary alveolar (type II) cells [3]. ACE2 is also highly expressed in the heart [6], where it can oppose the effects of angiotensin II in conditions with increased activation of the reninangiotensin system e.g., hypertension, congestive heart failure and atherosclerosis. As ACE2 is widespread in the human body, it provides a mechanism and the opportunity for SARS-CoV-2 to cause multiorgan dysfunction [6,7].

\section{Prognosis}

Initially, in the first 1-2 days of SARS-CoV-2 infection, the individual usually remains asymptomatic. Innate immune response is minimal and viral burden can be low, however it is still detectable by nasal swabs. Over a few days, the virus propagates and migrates down the respiratory tract and along the airways. As symptoms of COVID-19 manifest a more intense innate cytokine immune response is triggered [8]. Epithelial cells that are affected with the virus are a major source of beta and lambda interferons [9]. Another cytokine, namely C-X-C Motif Chemokine Ligand 10 (CXCL10) is an interferon responsive gene that has a cellular level response to both severe acute respiratory syndrome coronavirus and influenza and therefore is a useful disease marker [8]. If the disease is to progress to more severe forms, then patients may develop pulmonary infiltrates by way of the virus reaching the gaseous exchange units of the lung and infecting alveolar type II cells by gaining entry into the cell via ACE2. The virus propagates in these type II cells and then large numbers are released once the alveolar type II cells undergo cellular apoptosis and cell death [10]. The pathological result of both SARS and COVID-19 is diffuse alveolar damage [8].

A systematic review by Lovato [11] included five retrospective clinical studies, which included 1556 hospitalised patients with SARS-CoV-2, 57.5\% were male and the mean age was 49.1 years [11]. Common presenting symptoms were fever $(85.6 \%)$, cough $(68.7 \%)$, and fatigue (39.4\%). Their data also revealed that pharyngodynia was present in $12.4 \%$ of patients, nasal congestion in $3.7 \%$, and rhinorrhoea was rare.

\section{Risk factors and health determinants}

The Lovato study also reported that frequent comorbidities were hypertension $(17.4 \%)$, diabetes $(3.8 \%)$, and coronary heart disease $(3.8 \%), 83 \%$ of patients had changes on chest computed tomography scans, which were bilateral in $89.5 \%$ of cases. Ground-glass opacity was the most common finding (50\%). ${ }^{11}$ Laboratory investigations revealed that lymphopenia $(77.2 \%)$ and leucopenia $(30.1 \%)$ were common. Critical cases with complications were reported at $9 \%$, intensive care unit admission was needed in $7.3 \%$ of cases, and invasive ventilation in $3.4 \%$. Mortality was reported at 2.4\%. Comparable findings were reported by Pantea Stoian [12]. 


\section{Clinical presentation}

The majority $(81 \%)$ of SARS-CoV-2 cases are mild. Mild cases often lack changes in radiographical features [13]. Mild COVID-19 can present as symptoms of an upper respiratory tract viral infection, which includes a dry cough, nasal congestion, sneezing, sore throat, headache, malaise, muscle aches and pains, nausea, vomiting, abdominal pains, diarrhoea and fever [13]. Moderate disease presents with respiratory tract symptoms of cough, shortness of breath and tachypnoea and pneumonia [14], however they do not have any features of severe disease. Severe COVID-19 infection can present with symptoms of pulmonary embolism, thrombosis, severe dyspnoea, tachypnoea (respiratory rate $>30$ /minute) and respiratory distress, (Oxygen saturation $\left[\mathrm{SpO}_{2}\right] \leq 93 \%$, oxygen partial pressure/fractional inspired oxygen $(\mathrm{PaO} 2 / \mathrm{FiO} 2)<300$, and/or greater than $50 \%$ lung infiltrates within 24 to 48 hours). Fever can be absent or moderate. Presentation is that of severe pneumonia, acute respiratory distress syndrome (ARDS), sepsis and septic shock [14].

Of severely ill patients, $5 \%$ can develop critical disease with features of detectable serum SARS-CoV-2 viral load (RNAaemia), respiratory failure, cardiac injury (myocardial injury lesions and heart failure), encephalopathy, coagulation dysfunction, acute kidney injury, septic shock or multiple organ dysfunction. The reported fatality rate for critically ill patients was $49 \%$ [14]. It has also been reported that patients with pre-existing comorbidities have a higher fatality rate, these include cardiovascular disease $(10.5 \%)$, diabetes $(7.3 \%)$, respiratory disease $(6.5 \%)$, hypertension $(6 \%)$, and oncological complications (5.6\%). Patients without comorbidities have a slightly lower case fatality rate $(0.9 \%)$ [13].

\section{COVID-19 and patients diagnosed with cardiovascular diseases}

For this part of the review new search was conducted. The search included they key words - coronary heart disease, heart failure, myocardial infarction, cardiovascular disease, COVID-19 and SARS-Cov-2. Due to the lack of published RCTs on heart failure and COVID-19 at the time of the study; all studies that provided evidence for recommendations were retrospective and observational studies. The Cochrane Library, MEDLINE, EMBASE and PubMed were all searched. The search yielded a small number of studies which were related to cardiovascular disease and COVID-19.

The PICO (population, intervention, comparison, outcomes) tool was used to develop the review search key words (Box 1).

\section{Box 1}

Population: patients hospitalised with a COVID-19 diagnosis Interventions: Covide-19 management trials.

Comparaison: varions management stratégies

Outcomes: survival, mortality and COVID-19 diseases severity

There was main five studies identified, summarised in table I and discussed in the text of this review.

An observational study of 169 hospitals in Asia, Europe, and North America, explored the relationship between COVID-19, patients diagnosed with cardiovascular diseases (CVD) and drug therapy and in-hospital death among hospitalized patients who were admitted between December 20, 2019, and March 15, 2020 [15]. From the 8910 patients with COVID-19, a total of 515 died in the hospital $(5.8 \%)$ and 8395 survived to discharge. Factors found to be independently associated with an increased risk of in-hospital death were:

- Heart failure $(15.3 \%$, vs. $5.6 \%$ among those without heart failure; odds ratio, $2.48 ; 95 \%$ CI, 1.62 to 3.79 )

- Chronic obstructive pulmonary disease $(14.2 \%$, vs. $5.6 \%$ among those without disease; odds ratio, 2.96 ; 95\% CI, 2.00 to 4.40 )

- Cardiac arrhythmia (11.5\%, vs. 5.6\% among those without arrhythmia; odds ratio, $1.95 ; 95 \% \mathrm{CI}, 1.33$ to 2.86 )

- Coronary artery disease (10.2\%, vs. $5.2 \%$ among those without disease; odds ratio, $2.70 ; 95 \% \mathrm{CI}, 2.08$ to 3.51)

- Age greater than 65 years (mortality of $10.0 \%$, vs. $4.9 \%$ among those $\leq 65$ years of age; odds ratio, 1.93 ; $95 \%$ confidence interval [CI], CI 1.60 to 2.41 )

- Current smoker $(9.4 \%$, vs. 5.6\% among former smokers or non-smokers; odds ratio, $1.79 ; 95 \%$ CI, 1.29 to 2.47).

- No increased risk of in-hospital death was found to be associated with the use of ACE inhibitors $(2.1 \%$ vs. $6.1 \%$; odds ratio, 0.33 ; $95 \% \mathrm{CI}, 0.20$ to 0.54 ) or ARBs (6.8\% vs. $5.7 \%$; odds ratio, $1.23 ; 95 \% \mathrm{CI}, 0.87$ to 1.74 ).

Exploring the link between COVID-19 and CVD may perhaps provide an insight into possible preventative steps that can be taken in this patient group. Overall, from recent studies, myocardial injury from COVID-19 can be explained by two mechanisms:

- Myocardial injury can result from the associated cytokine storm caused by elevated levels of interleukin- 6 (IL-6), ferritin, lactate dehydrogenase (LDH), and D-dimer. This imbalanced response among subtypes of T-helper cells and hypoxia-induced excessive intracellular calcium can lead to cardiac myocyte apoptosis [16].

- Myocardial dysfunction can result from the direct effect of SARS-CoV-2 on the heart which is mediated by a reduction of the protective effects of ACE2 [17]. 
Table I. Reviwed papers overview (direct qoutation).

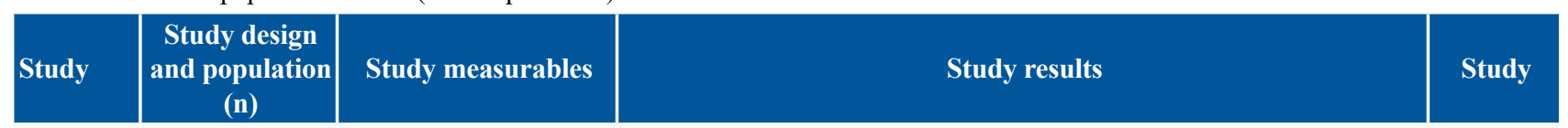

\begin{tabular}{|c|c|c|c|c|}
\hline $\begin{array}{l}\text { Mehra et } \\
\text { al., } 2020\end{array}$ & $\begin{array}{l}\text { Observational } \\
\text { study } \\
\mathrm{n}=8910\end{array}$ & $\begin{array}{l}\text { Reviewing COVID-19 } \\
\text { in correlation with } \\
\text { cardiovascular disease, } \\
\text { drug therapy and } \\
\text { mortality }\end{array}$ & $\begin{array}{l}\text { The study identified specific factors that were found to be } \\
\text { independently associated with an increased risk of in-hospital death, } \\
\text { these included - age greater than } 65 \text { years (mortality of } 10.0 \% \text {, vs. } \\
4.9 \% \text { among those } \leq 65 \text { years of age; odds ratio, } 1.93 ; 95 \% \text { confidence } \\
\text { interval [CI], } 1.60 \text { to } 2.41 \text { ), coronary artery disease ( } 10.2 \% \text {, vs. } 5.2 \% \\
\text { among those without disease; odds ratio, } 2.70 ; 95 \% \text { CI, } 2.08 \text { to } 3.51 \text { ), } \\
\text { heart failure ( } 15.3 \% \text {, vs. } 5.6 \% \text { among those without heart failure; odds } \\
\text { ratio, } 2.48 ; 95 \% \text { CI, } 1.62 \text { to } 3.79 \text { ), cardiac arrhythmia ( } 11.5 \% \text {, vs. } 5.6 \% \\
\text { among those without arrhythmia; odds ratio, } 1.95 ; 95 \% \text { CI, } 1.33 \text { to } \\
\text { 2.86), chronic obstructive pulmonary disease ( } 14.2 \% \text {, vs. } 5.6 \% \text { among } \\
\text { those without disease; odds ratio, } 2.96 ; 95 \% \text { CI, } 2.00 \text { to } 4.40 \text { ), and } \\
\text { current smoking status }(9.4 \% \text {, vs. } 5.6 \% \text { among former smokers or non- } \\
\text { smokers; odds ratio, } 1.79 ; 95 \% \text { CI, } 1.29 \text { to } 2.47 \text { ). }\end{array}$ & $\begin{array}{l}\text { Mehra et } \\
\text { al., } 2020\end{array}$ \\
\hline $\begin{array}{l}\text { Meng et } \\
\text { al., } 2020\end{array}$ & $\begin{array}{l}\text { Retrospective } \\
\text { review } \\
n=417\end{array}$ & $\begin{array}{l}\text { Reviewing the effect } \\
\text { of renin-angiotensin } \\
\text { system inhibitors on } \\
\text { COVID-19 outcomes }\end{array}$ & $\begin{array}{l}\text { Patients receiving ACE inhibitors or ARB therapy had a lower rate } \\
\text { of severe diseases and a lower level of IL- } 6 \text { in peripheral blood. } \\
\text { Furthermore, ACE inhibitors or ARB therapy increased CD3 and CD8 } \\
\text { T cell counts in peripheral blood and decreased the peak viral load } \\
\text { compared to other antihypertensive drugs. }\end{array}$ & $\begin{array}{l}\text { Meng et } \\
\text { al., } 2020\end{array}$ \\
\hline $\begin{array}{l}\text { Ruan et } \\
\text { al., } 2020\end{array}$ & $\begin{array}{l}\text { Retrospective } \\
\text { multicentre } \\
\text { study } \\
\mathrm{n}=150\end{array}$ & $\begin{array}{l}\text { Reviewing clinical } \\
\text { predictors of mortality } \\
\text { due to COVID-19 }\end{array}$ & $\begin{array}{l}\text { Predictors of a fatal outcome in COVID-19 cases included age, the } \\
\text { existence of underlying diseases, the presence of secondary infection } \\
\text { and elevated inflammatory indicators in the blood. }\end{array}$ & $\begin{array}{l}\text { Ruan et } \\
\text { al., } 2020\end{array}$ \\
\hline $\begin{array}{l}\text { Shi et al., } \\
2020\end{array}$ & $\begin{array}{l}\text { Retrospective } \\
\text { cohort study } \\
\mathrm{n}=416\end{array}$ & $\begin{array}{l}\text { To explore the } \\
\text { association between } \\
\text { cardiac injury and } \\
\text { mortality in patients } \\
\text { with COVID-19. }\end{array}$ & $\begin{array}{l}\text { Cardiac injury is a common condition among hospitalized patients with } \\
\text { COVID-19. Complications were more common in patients with cardiac } \\
\text { injury than those without cardiac injury and included acute respiratory } \\
\text { distress syndrome, acute kidney injury, electrolyte disturbances, } \\
\text { hypoproteinaemia and coagulation disorders. }\end{array}$ & $\begin{array}{l}\text { Shi et al., } \\
2020\end{array}$ \\
\hline $\begin{array}{l}\text { Guo et al., } \\
2020\end{array}$ & $\begin{array}{l}\text { Retrospective } \\
\text { single-centre } \\
\text { case series } \\
\mathrm{n}=187\end{array}$ & $\begin{array}{l}\text { To assess the association } \\
\text { of underlying } \\
\text { cardiovascular disease } \\
\text { and myocardial injury } \\
\text { with fatal outcomes } \\
\text { in patients with } \\
\text { COVID-19. }\end{array}$ & $\begin{array}{l}\text { Myocardial injury was found to be significantly associated with fatal } \\
\text { outcomes of COVID-19. Furthermore, it was found that the prognosis } \\
\text { of patients with underlying cardiovascular disease without myocardial } \\
\text { injury is relatively favourable. Myocardial injury is associated with } \\
\text { cardiac dysfunction and arrhythmias. Inflammation was identified as a } \\
\text { potential mechanism for myocardial injury. }\end{array}$ & $\begin{array}{l}\text { Guo et al., } \\
2020\end{array}$ \\
\hline
\end{tabular}

ACE2 has been the subject of debate during the COVID-19 pandemic and initially there were conflicting studies on whether angiotensin converting enzyme inhibitor (ACEi) and an angiotensin receptor blocker (ARB) drugs increase or exert any effect on ACE2 levels [16]. The use of ACEi and ARB drugs is common practice in cardiovascular disorders (hypertension, coronary artery disease, congestive heart failure) and in diabetes mellitus [18]. A study conducted in a murine model, demonstrated that the binding of the SARS-CoV spike protein to ACE2 caused ACE2 downregulation, which led to an increase in angiotensin II and subsequently increased pulmonary vascular permeability, causing pulmonary oedema and reduced lung function [17]. Due to these mechanisms, new clinical concerns understandably developed regarding whether patients taking ACEi and ARB medications were at increased risk of SARS-CoV-2 infection.

ACE2 is a homolog of ACE - it acts to degrade/ convert angiotensin II (a peptide with multiple actions that promote CVD), to angiotensin 1-7; which opposes the effects of angiotensin II; it therefore serves to reduce vasoconstriction mediated by the Renin-Angiotensin System (RAS). As the S-protein of the SARS-CoV-2 binds to the ACE2 on cell membranes of the lungs, heart, and kidneys, and gains entry into the cells, ultimately causing cell death - therefore, ACE2 is selectively destroyed by SARS-CoV-2, leading to an increase of angiotensin II. This precipitates promotion/worsening of CVD through various mechanisms, which can be hypothesised as one of the reasons for the increase in mortality in CVD patients. Due 
to the selective affinity of SARS-CoV-2 for ACE2 cells, an imbalance in the RAS pathways arises [19].

The ACE2 pathway promotes anti-fibrosis, antiinflammatory, anti-atrophy, anti-oxidant and vasodilatory effects and ultimately leading to tissue protection. The ACE pathway has counter effects causing pro-fibrosis, proinflammatory, pro-atrophy, pro-oxidant and vasoconstriction effects, leading ultimately to tissue injury [19].

The study by Meng [19], has recently stated that they have found the first clinical evidence demonstrating that RAS inhibitors (ACEi and ARB medications), improve the clinical outcomes of COVID-19 patients with hypertension, suggesting that this patient group would benefit from continued or preferential usage of ACEi/ ARB drugs for hypertension [18]. The study explained that COVID-19 patients with hypertension who were taking ACEi/ARB medications, had a weakened inflammatory response, thought to be through the inhibition of IL-6 levels which is supported by evidence that demonstrated that ACEi and ARB medications reduce lipopolysaccharideinduced pneumonic injury [18]. The study also proposes that ACEi/ARB medications have a beneficial effect on the immune system by avoiding peripheral $\mathrm{T}$ cell depletion and also cause a decrease in the viral load, which was explained by the way of indirect antiviral activity of the RAS on inhibiting anti-inflammatory responses and regulating immune function. One would assume that due to the inhibition of the ACE pathway by current ACEi and ARB medications, the corresponding ACE2 pathway would still be active, therefore exhibiting protective mechanisms as described above [20].

ACE2 expression in the heart is a key regulator of function. In animal models, when ACE2 has been removed, mice develop severe left ventricular dysfunction [21]. As SARS-CoV-2 causes destruction of ACE2, this is thought to be a contributary factor to myocardial dysfunction [22]. Cardiac involvement in COVID-19 is associated with a worse prognosis. Patients with more severe disease, requiring ICU admission have been found to have elevated cardiac troponin I and BNP levels [23]. In Wuhan, it has been reported that myocardial damage and heart failure contributed to $40 \%$ of deaths, either alone or in combination with respiratory failure [24].

The retrospective multicentre study by Ruan [24] included 150 patients with laboratory confirmed SARSCoV-2 infection. A total of $63 \%$ of patients in the death group and $41 \%$ in the discharge group had underlying diseases $(p=0.0069)$, with cardiovascular diseases were leading to a significant increased risk of death when infected with SARS-CoV-2 $(p<0.001)$. These results highlight the population with CVD as high risk for COVID-19 infection.

A cohort study conducted by Shi [25], including 416 patients, showed that cardiac injury occurred in $19.7 \%$ of patients during hospital stay and was also identified as an independent risk factor for in-hospital mortality [24]. The median age was 64 years (range: 21-95 years) and 211 patients $(50.7 \%)$ were female. Common symptoms included fever (334 patients [80.3\%]), cough (144 [34.6\%]), and shortness of breath $(117$ [28.1\%]). A total of 82 patients $(19.7 \%)$ had cardiac injury and a higher mortality rate compared to patients with no cardiac injury $(51.2 \%$ vs. $4.5 \% ; P<0.001$ ). These patients were older (median age 74 vs. 60 years; $P<.001$ ), diagnosed with hypertension (59.8\% vs. $23.4 \% ; P<.001)$, had higher levels of highsensitivity troponin I (median 0.19 vs. $<0.006 \mu \mathrm{g} / \mathrm{L}$ ) and higher N-terminal pro-B-type natriuretic peptide (median 1689 vs. $139 \mathrm{pg} / \mathrm{mL}$ ).

Out of the patients with cardiac injuries, 38 required respiratory support (non-invasive mechanical ventilation) and 18 patients required invasive mechanical ventilation versus vs. 13 and 14 out of the study total population who did not have cardiac injuries $(P<0.001, P<0.001$ respectively). Patients had cardiac injuries also had more complications, including adverse drug reactions $(58.5 \%$ vs $14.7 \% ; P<0.001)$, acute kidney injury ( $8.5 \%$ vs $0.3 \%$; $P<0.001)$, electrolyte disturbances $(15.9 \%$ vs $5.1 \%$; $P=0.003)$, hypoproteinaemia $(13.4 \%$ vs $4.8 \% ; P=0.01)$, and coagulation disorders $(7.3 \%$ vs $1.8 \% ; P=0.02)$. This suggest that within the population of patients with CVD, those with cardiac injuries constitute the highest risk group.

A retrospective, single-centre, case series study of 187 patients with COVID-19 by Guo [26] aimed to evaluate the association of underlying CVD and myocardial injury with fatal outcomes in patients with COVID-19. ${ }^{25}$ From the 187 patients, $23 \%$ died. The mean age was 58.50 years and $35.3 \%$ had underlying CVD (including hypertension, coronary heart disease, and cardiomyopathy). 27.8\% developed myocardial injury (indicated by raised cardiac troponin levels). Mortality during hospitalisation was $7.62 \%$ for patients without underlying CVD and with normal troponin levels and $13.33 \%$ for those with underlying CVD and normal troponin levels, with $37.50 \%$ of the patients did not have underlying CVD but had elevated troponin levels and $69.44 \%$ of patients with CVD had elevated troponin.

Overall, it was reported that patients with underlying CVD were more likely to demonstrate an elevation of troponin levels compared to patients without CVD (36 [54.5\%] vs 16 [13.2\%]). The plasma troponin levels exhibited a high and significantly positive linear correlation with plasma $C$-reactive protein levels $(P<0.001)$ and $\mathrm{N}$-terminal pro-brain natriuretic peptide levels $(P<0.001)$.

\section{Conclusion}

Myocardial injury has thus been shown to have a considerable association with mortality outcomes for SARS-CoV-2 infection. Interestingly this study stated that the prognosis of patients with underlying CVD, who had not sustained myocardial injury was relatively favourable. Myocardial injury is associated with cardiac dysfunction and arrhythmias. Inflammation may also be a potential 
mechanism for myocardial injury. Current evidence suggests statistically significant associations between cardiac injury and mortality in patients with COVID-19. Whether this is mediated by destruction of ACE2 in heart cells or by other mechanisms, is still being investigated. In patients with underlying CVD, aggressive treatment for COVID-19 should be considered and clinicians should be aware of the significant increased risk of serious infection and worse prognosis in this patient group.

New studies are continually being published, further investigations will continue to be carried out to confirm or refute current understanding around SARS-CoV-2.

Primary care practitioners are urged to continue to monitor the evolving evidence to appropriately manage their patients who are at risk of, or currently diagnosed with cardiovascular conditions.

\section{References}

1. Fehr AR, Perlman S. Coronaviruses: an overview of their replication and pathogenesis. Methods Mol Biol. 2015;1282:1-23.

2. Millet JK, Whittaker GR. Host cell proteases: Critical determinants of coronavirus tropism and pathogenesis. Virus Res. 2015;202:120-134.

3. Yuki K, Fujiogi M, Koutsogiannaki S. COVID-19 pathophysiology: Areview. Clin Immunol. 2020;215:108427.

4. Wallinga J, Teunis P. Different epidemic curves for severe acute respiratory syndrome reveal similar impacts of control measures. Am J Epidemiol. 2004;160:509-516.

5. Lauer SA, Grantz KH, Bi Q, Jones FK, Zheng Q, Meredith $\mathrm{HR}$, et al. The Incubation Period of Coronavirus Disease 2019 (COVID-19) From Publicly Reported Confirmed Cases: Estimation and Application. Ann Intern Med. 2020;172:577-582.

6. Apetrii M, Enache S, Siriopol D, Burlacu A, Kanbay A, Kanbay M, et al. A brand-new cardiorenal syndrome in the COVID-19 setting. Clin Kidney J. 2020;13:291-296.

7. Tikellis C, Thomas MC. Angiotensin-Converting Enzyme 2 (ACE2) Is a Key Modulator of the Renin Angiotensin System in Health and Disease. Int J Pept. 2012;2012:256294.

8. Mason RJ. Pathogenesis of COVID-19 from a cell biology perspective. Eur Respir J. 2020;55:2000607.

9. Hancock AS, Stairiker CJ, Boesteanu AC, Monzón-Casanova E, Lukasiak S, Mueller YM, et al. Transcriptome Analysis of Infected and Bystander Type 2 Alveolar Epithelial Cells during Influenza A Virus Infection Reveals In Vivo Wnt Pathway Downregulation. J Virol. 2018;92:e01325-e01318.

10. Qian Z, Travanty EA, Oko L, Edeen K, Berglund A, Wang $\mathrm{J}$, et al. Innate immune response of human alveolar type II cells infected with severe acute respiratory syndromecoronavirus. Am J Respir Cell Mol Biol. 2013;48:742-748.

11. Lovato A, de Filippis C. Clinical Presentation of COVID-19: A Systematic Review Focusing on Upper Airway Symptoms. Ear Nose Throat J. 2020;99:569-576.

12. Pantea Stoian A, Pricop-Jeckstadt M, Pana A, Ileanu
B, Schitea R, Geanta M, et al. Death by SARS-CoV 2: a Romanian COVID-19 multi-centre comorbidity study. Sci Rep. 2020;10:21613.

13. Wang Y, Wang Y, Chen Y, Qin Q. Unique epidemiological and clinical features of the emerging 2019 novel coronavirus pneumonia (COVID-19) implicate special control measures. J Med Virol. 2020;92:568-576.

14. Cascella M, Rajnik M, Cuomo A, Dulebohn SC, Di Napoli R. Features, Evaluation, and Treatment of Coronavirus. StatPearls Treasure Island (FL): StatPearls Publishing LLC; 2020.

15. Mehra MR, Desai SS, Kuy S, Henry TD, Patel AN. Retraction: Cardiovascular Disease, Drug Therapy, and Mortality in Covid-19. N Engl J Med. DOI: 10.1056/NEJMoa2007621. N Engl J Med. 2020;382:2582.

16. Zhou F, Yu T, Du R, Fan G, Liu Y, Liu Z, et al. Clinical course and risk factors for mortality of adult inpatients with COVID-19 in Wuhan, China: a retrospective cohort study. Lancet. 2020;395:1054-1062.

17. Clerkin KJ, Fried JA, Raikhelkar J, Sayer G, Griffin JM, Masoumi A, et al. COVID-19 and Cardiovascular Disease. Circulation. 2020;141:1648-1655.

18. Ferrario CM, Jessup J, Chappell MC, Averill DB, Brosnihan $\mathrm{KB}$, Tallant EA, et al. Effect of angiotensin-converting enzyme inhibition and angiotensin II receptor blockers on cardiac angiotensin-converting enzyme 2. Circulation. 2005;111:2605-2610.

19. Meng J, Xiao G, Zhang J, He X, Ou M, Bi J, et al. Reninangiotensin system inhibitors improve the clinical outcomes of COVID-19 patients with hypertension. Emerg Microbes Infect. 2020;9:757-760.

20. Zheng YY, Ma YT, Zhang JY, Xie X. COVID-19 and the cardiovascular system. Nat Rev Cardiol. 2020;17:259-260.

21. Crackower MA, Sarao R, Oudit GY, Yagil C, Kozieradzki I, Scanga SE, et al. Angiotensin-converting enzyme 2 is an essential regulator of heart function. Nature. 2002;417:822828.

22. Oudit GY, Kassiri Z, Jiang C, Liu PP, Poutanen SM, Penninger JM, et al. SARS-coronavirus modulation of myocardial ACE2 expression and inflammation in patients with SARS. Eur J Clin Invest. 2009;39:618-625.

23. Arentz M, Yim E, Klaff L, Lokhandwala S, Riedo FX, Chong $\mathrm{M}$, et al. Characteristics and Outcomes of 21 Critically Ill Patients With COVID-19 in Washington State. JAMA. 2020;323:1612-1614.

24. Ruan Q, Yang K, Wang W, Jiang L, Song J. Clinical predictors of mortality due to COVID-19 based on an analysis of data of 150 patients from Wuhan, China. Intensive Care Med. 2020;46:846-848.

25. Shi S, Qin M, Shen B, Cai Y, Liu T, Yang F, et al. Association of Cardiac Injury With Mortality in Hospitalized Patients With COVID-19 in Wuhan, China. JAMA Cardiol. 2020;5:802-810.

26. Guo T, Fan Y, Chen M, Wu X, Zhang L, He T, et al. Cardiovascular Implications of Fatal Outcomes of Patients With Coronavirus Disease 2019 (COVID-19). JAMA Cardiol. 2020;5:811-818. 